\title{
Best color Doppler indices in prediction of fetal hypoxia in IUGR fetuses
}

\author{
Netam SBS ${ }^{1}$, Abha $\mathbf{S}^{2}$, Mandle $\mathbf{H}^{3}$, Dutt $\mathbf{V}^{4}$, Kumar $\mathbf{S}^{5}$, Singh $\mathbf{R}^{6}$ \\ ${ }^{1}$ Dr Satya bhuwan singh Netam, Associate professor, Pt JNM Medical College Raipur, CG, India, ${ }^{2}$ Dr Abha Singh, Pt \\ JNM Medical College Raipur, CG, India, ${ }^{3}$ Dr Hulesh Mandle, Pt JNM Medical College Raipur, CG, India, ${ }^{4}$ Dr Vishnu \\ Dutt, Professor/Dean, CIMS Bilaspur, Chhattisgarh, India, , ${ }^{5}$ Dr Sanjay Kumar, Associate professor, Pt JNM Medical \\ College Raipur, CG, India, ${ }^{6}$ Dr Rajesh Singh, Pt JNM Medical College Raipur, CG, India.
}

Address for Correspondence: Dr SBS Netam, Email: sbsnetam@yahoo.com, D-20, Avani Vihar, Daldalseoni Road Mova, Raipur, Chhattishgarh, India.

\begin{abstract}
Objective: To determine the best predictor of fetal hypoxia amongst the color Doppler indices resistivity index(RI), pulsality index(PI) and systolic/ diastolic (S/D) ration of umbilical artery (UA), middle cerebral artery(MCA), descending abdominal aorta (DAA), MCA/UA PI ratio and abnormal flow pattern, absent end diastolic flow/reverse end diastolic flow (AEDF/REDF) in umbilical artery and descending abdominal aorta, in prediction of adverse perinatal outcome in normal and intrauterine growth retardation (IUGR) fetuses with or without pregnancy induced hypertension (PIH). Material and Method: 100 women with normal Singleton pregnancies and 100 women with IUGR with or without PIH or both were prospectively examined with Doppler Ultrasonography of the umbilical artery, middle cerebral artery \& descending abdominal aorta and perinatal outcomes was evaluated in relation to their indices and compared with each other. Observation: In study group sixty four fetuses $(64 \%)$ had one major or minor adverse perinatal outcome in comparison to control group which had only $6 \%$ adverse perinatal outcome. In study group premature delivery was $46 \%$, lower segment cesarean section (LSCS) was 38\%, and perinatal death was 22\%. Fetuses with absent end diastolic flow/reverse end diastolic flow (AEDF/REDF) in umbilical artery and descending abdominal aorta had $100 \%$ perinatal mortality. Conclusion: Umbilical artery SD Ratio (cut off $\geq 3$ ), middle cerebral artery / umbilical artery PI < 1.08, AEDF / REDF abnormal flow pattern in umbilical artery and descending abdominal aorta were found to be the best Doppler indices for prediction of adverse perinatal outcome in women with PIH and IUGR.
\end{abstract}

Keywords: Color Doppler indices, Intrauterine Growth Restriction, Middle Cerebral Artery, Perinatal Outcome, Umbilical Artery.

\section{Introduction}

Establishment of a good utero-placental circulation is necessary for normal pregnancy [1]. Initially when the placenta is small and utero-placental circulation is not developed, there is high resistance flow in umbilical artery, as pregnancy advances utero-placental circulation is well established S/D ratio of umbilical artery decreases [2]. Failure in establishment of a good utero-placental circulation due to any region fetal development become restricted and leads to intrauterine

Manuscript received: ${ }^{1 \text { st }}$ Sept 2015

Reviewed: $20^{\text {th }}$ Sept 2015

Author Corrected: $28^{\text {th }}$ Sept 2015

Accepted for Publication: $3^{\text {rd }}$ Oct 2015 growth retardation (IUGR). IUGR is associated with an increased risk of perinatal mortality, morbidity, and impaired neurodevelopment [1]. PIH (preeclampsia) is the commonest cause of utero-placental insufficiency. Delivery is the only cure for preeclampsia for the mother but it may not be optimal for premature fetus before 34 weeks of gestation. To avoid inappropriate early intervention it is necessary to make an accurate assessment of fetal well being. The role of color Doppler is to detect these abnormal vascular resistance patterns and thus to detect the compromised fetus [3]. Here we try to find out the best predictor amongst the color Doppler indices to predict the fetal hypoxia and thus adverse fetal outcome in IUGR and normal fetuses. 


\section{Material and Methods}

This is a Prospective comparative study conducted between August 2008 to August 2009, in the Department Of Radiodiagnosis and Imaging in Pt. J.N.M. medical College and associated Dr BRAM Hospital, Raipur, CG.

The population comprised of 200 pregnancies. Out of 200 women, 100 women showing normal fetal growth parameters \& normal maternal blood pressure were included in the control group and 100 women showing abdominal circumference less than $10^{\text {th }}$ percentile for their gestational age or pre-eclamptic mother were included in the study group.

Gestational age determination was based on a best estimate from menstrual history, clinical gestational age. Pregnancy with unknown LMP, Pregnancies with multiple gestations and congenital anomalies were excluded from the study.

The ultrasound machine used was Aloka Prosound (MODEL -SSD4000) Color Doppler machine with a transduser frequency was $3.5 \mathrm{MHz}$. The Doppler waveform and PI, RI and S/D ration indices of Umbilical Artery (UA), Middle Cerebral Artery (MCA), Descending Abdominal Aorta (DAA) were studied with the mother in supine position during fetal inactivity and apnea. All vessels were examined in the standard plane.
We followed the reference value of different authors for the abnormal indices. Doppler indices were considered abnormal when- (1).Umbilical artery pulsatility index more than 95 percentile [4]. (2).Umbilical artery S/D ratio more than 3 or more than 95 percentile [5]. (3) Middle cerebral artery pulsatility index less than 5 percentile [6]. (4). Descending abdominal aorta pulsatility index greater than 95 percentile [4].

The ratio examined were considered abnormal when(1) MCA/UA PI ratio less than 1.08 or less than 2SD [4]. (2) MCA/UA S/D ratio less than 1[7]. Fetal outcome was divided into major and minor adverse outcome. The major outcome included the stillbirths, early neonatal death, prolonged NICU admission (>7days), hypoxic ischemic encephalopathy (HIE), intracranial hemorrhage ( $\mathrm{ICH})$, necrotizing enterocolitis (NEC), and congestive cardiac failure (CCF). The minor outcome included LSCS for fetal hypoxia, preterm delivery ( $<37$ weeks) and Apgar score at $5 \mathrm{~min}$ $<7[8]$.

The patients were followed by serial Doppler assessment and the result of the last Doppler examination within 14 days of delivery was considered in the subsequent correlation with perinatal outcomes. All the indices and ratios of the study and control group were analyzed and compared with validity of test and chi test.

\section{Result}

In study group sixty four fetuses $(64 \%)$ had adverse perinatal outcome in comparison to control group which had only $6 \%$ adverse perinatal outcome.

Table No1: Adverse perinatal outcomes

\begin{tabular}{|l|l|l|l|l|l|l|l|}
\hline \multicolumn{2}{|c|}{ Adverse Perinatal outcome indicator* } & $\begin{array}{l}\text { Study } \\
\text { No. }\end{array}$ & $\begin{array}{l}\text { Control } \\
\text { No. }\end{array}$ & $\begin{array}{l}\text { Total } \\
\text { No. }\end{array}$ & $\begin{array}{l}\chi^{2} \\
\text { value }\end{array}$ & P value & Si \\
\hline Major & & & & & & \\
\hline 1 & Stillbirth & 12 & 0 & 12 & 6.383 & 0.012 & S \\
\hline 2 & Neonatal death & 10 & 0 & 10 & 5.263 & 0.022 & S \\
\hline 3 & NICU admission $>7$ days & 18 & 2 & 20 & 3.840 & 0.05 & S \\
\hline 4 & HIE & 4 & 0 & 4 & 2.041 & 0.153 & NS \\
\hline 5 & ICH & 4 & 0 & 4 & 2.041 & 0.153 & NS \\
\hline 6 & NEC & 2 & 0 & 2 & 1.010 & 0.315 & NS \\
\hline 7 & CCF & 2 & 0 & 2 & 1.010 & 0.315 & NS \\
\hline Minor & & & & & & & \\
\hline 8 & LSCS for fetal distress & 32 & 2 & 34 & 15.946 & 0.000 & HS \\
\hline 9 & Premature birth & 46 & 4 & 50 & 23.520 & 0.000 & HS \\
\hline 10 & 5-min Apgar score $<7$ & 20 & 2 & 22 & 8.274 & 0.004 & HS \\
\hline
\end{tabular}


* - One newborn can have more than one adverse outcome

$\mathrm{Si}=$ Significance; $\mathrm{S}=$ Significant; NS= Not Significant; HS= Highly Significant

$\mathrm{HIE}=$ Hypoxic Ischemic Encephalopathy; $\mathrm{ICH}=$ Intracranial Hemorrhage;

$\mathrm{NEC}=$ Necrotizing Enterocolitis; $\mathrm{CCF}=$ Congestive Cardiac Failure

We found major adverse outcome as still birth 12, neonatal death 10 and NICU admission for > 7days 18 in study group while no still birth, no neonatal death and 2 NICU admission for $>7$ days in control group with p value $-0.012,0.022$ and 0.05 with statistically significant result. Other major perinatal outcome were HIE (Hypoxic ischemic encephalopathy), Intracranial Hemorrhage (ICH), Necrotising necrocolitis (NEC) and Congestive cardiac failure (CCF) with numbers 4, 4, 2 and 2 respectively. $\mathrm{P}$ values of all were more then 0.05 and were statistically insignificant. We found minor adverse outcome as LSCS for fetal distress, Premature birth and 5-min APGAR score <7 with numbers -32, 46, 20 in study group and numbers $-2,4,2$ in control group respectively with $p$ value -0.00 in first two and 0.004 in last one. They were statistically highly significant. [Table-1].

Table No 2: Adverse [major + minor] perinatal outcome of study population according to doppler indices : performance characteristics

\begin{tabular}{|l|l|l|l|l|l|}
\hline \multirow{2}{*}{ Criterion } & \multirow{2}{*}{ Sensitivity } & \multirow{2}{*}{ Specificity } & \multicolumn{2}{l|}{ Predictive value } & \multirow{2}{*}{ Accuracy } \\
\cline { 4 - 5 } & & & +ve & -ve & \\
\hline UA PI $\geq 95$ percentile & 80 & 70.77 & 59.57 & 86.79 & 74 \\
\hline UA S/D $\geq 3$ & 86.96 & 71.21 & 51.28 & 94 & 75.28 \\
\hline UA S/D $\geq 95$ percentile & 69.57 & 78.78 & 53.33 & 88.14 & 76.40 \\
\hline MCA PI < 5 percentile & 47.06 & 81.81 & 57.14 & 75 & 70 \\
\hline DAA PI $\geq 95$ percentile & 44.4 & 59 & 64 & 56.5 & 72.50 \\
\hline MCA/UA PI < [mean - 2SD] & 77.14 & 83.08 & 71.05 & 87.10 & 81 \\
\hline MCA/UA PI < 1.08 & 73.53 & 89.40 & 78.12 & 86.76 & 84 \\
\hline MCA/UA [S/D] $<1$ & 47.83 & 84.84 & 52.38 & 82.35 & 75.28 \\
\hline AEDF/REDF UA & 34.37 & 100 & 100 & 76.40 & 79 \\
\hline AEDF/REDF DAA & 33.47 & 100 & 100 & 76.30 & 78 \\
\hline
\end{tabular}

In prediction of adverse perinatal outcome in IUGR fetuses umbilical artery S/D ratio $\geq 3$ had highest sensitivity $(86.96 \%)$ followed by umbilical artery PI $\geq 95$ percentile $(80 \%)$. While the specificity and positive predictive value in prediction of adverse perinatal outcome in IUGR fetuses was highest in AEDF/REDF in UA and DAA (100\% each) followed by MCA/UA PI ratio <1.08 with sensitivity of $89.40 \%$ and positive predictive value of $78.12 \%$. Highest negative predictive value was fond in UA S/D >3 with (94\%). Highest accurate Doppler indices in prediction of adverse perinatal outcome in IUGR fetuses was MCA/UA PI ratio with $<1.8$ with $(84 \%)$ [Table-2].

Table No 3: Adverse [only major] perinatal outcome of study population according to Doppler indices: performance characteristics

\begin{tabular}{|l|l|l|l|l|l|}
\hline Criterion & Sensitivity & Specificity & \multicolumn{2}{l|}{ Predictive value } & \multirow{2}{*}{ Accuracy } \\
\cline { 4 - 5 } & & & +ve & -ve & \\
\hline UA PI $\geq 95$ percentile & 94.74 & 62.96 & 37.5 & 98.08 & 69 \\
\hline UA S/D $\geq 3$ & 100 & 61.73 & 20.51 & 100 & 65.17 \\
\hline UA S/D $\geq 95$ percentile & 87.5 & 71.6 & 23.33 & 98.30 & 73.03 \\
\hline MCA PI < 5 percentile & 63.16 & 81.48 & 41.38 & 90.14 & 76 \\
\hline DAA PI $\geq 95$ percentile & 41.6 & 56 & 21.76 & 91.7 & 53.4 \\
\hline MCA/UA PI < [mean - 2SD] & 89.47 & 75.31 & 45.94 & 96.83 & 78 \\
\hline MCA/UA PI <1.08 & 89.47 & 81.48 & 53.13 & 97.06 & 83 \\
\hline MCA/UA [S/D]<1 & 75 & 81.48 & 28.57 & 97.06 & 80.90 \\
\hline AEDF/REDF UA & 57.89 & 100 & 100 & 90 & 92 \\
\hline AEDF/REDF DAA & 56.66 & 100 & 100 & 89 & 90 \\
\hline
\end{tabular}


In prediction of only major adverse outcome umbilical artery S/D ratio with cut off value of 3 had highest sensitivity (100\%) and negative predictive value (100\%) while AEDF/REDF in UA and DAA had highest specificity(100\%), Positive predictive value(100\%) and accuracy (92\%) followed by MCA/UA PI ratio with cut off value of 1.08 $(83 \%)$ [Table 3].

In our study Mean 'diagnosis to delivery' interval in control group was 2.72 weeks while in study group it was 1.24 weeks. Mean birth weights in study and control groups were $2781 \pm 197$ gm and $1621 \pm 321$ gm respectively.

\section{Discussion}

In normal pregnancy, the indices; S/D and Pl decrease with advancing gestation in descending fetal aorta \& Umbilical artery (fig-1), But in IUGR first there is decreased diastolic flow in the umbilical artery due to increase in the resistance that occurs in small arteries and arterioles of the tertiary villi [9][10][11]. This raises the S/D ratio and Pl of umbilical artery. As the placental insufficiency worsen, the diastolic flow decreases, then become absent (fig-2), and later reverse(fig-3) flow pattern noted on descending fetal aorta \& umbilical artery [12][13].

\section{Fig 1: Umbilical artery normal velocimetry}

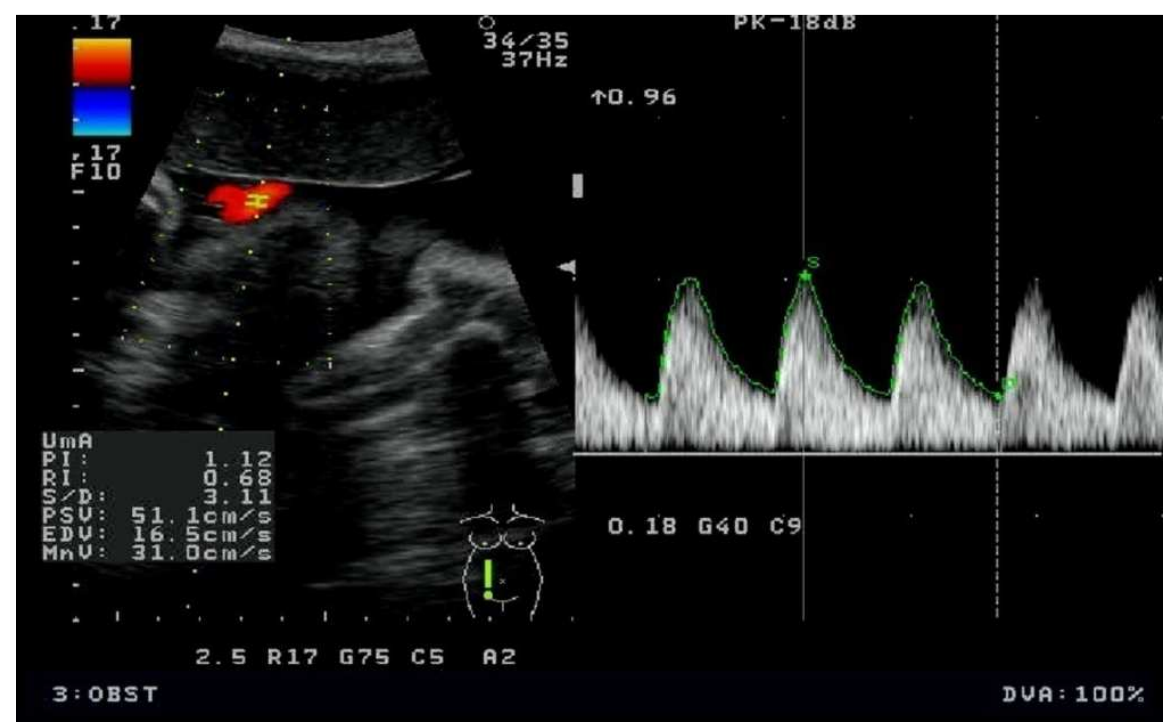

Fig 2: Absent diastolic flow in Umbilical artery

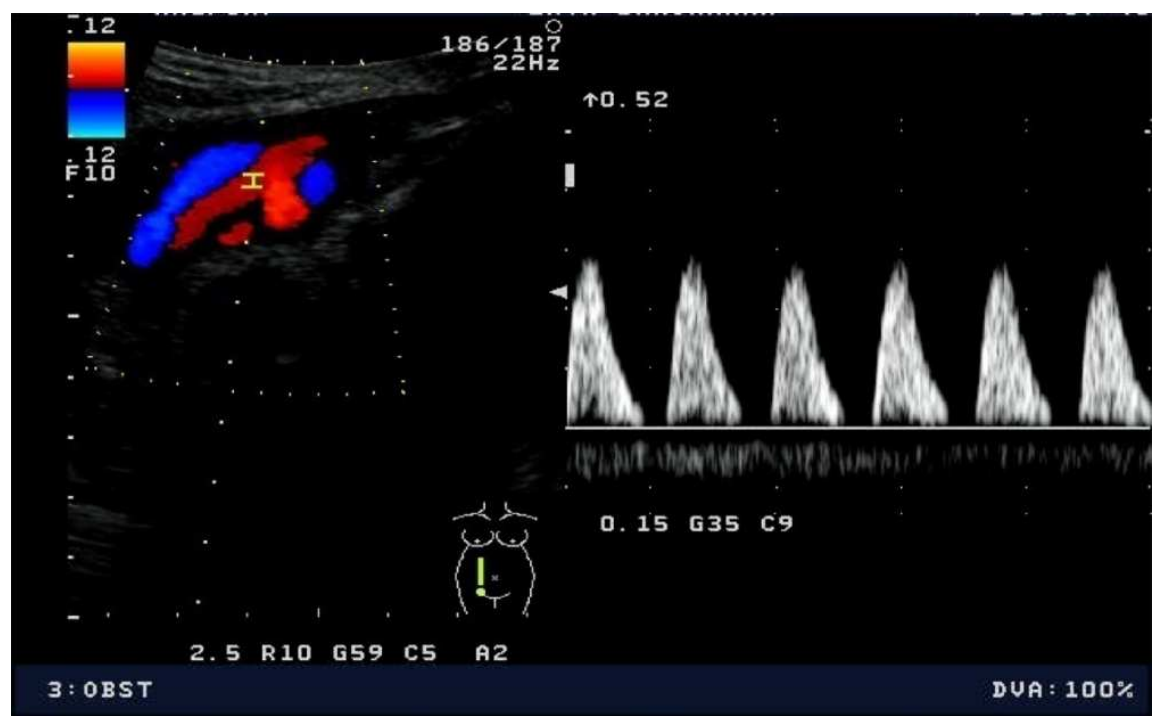


Fig 3: Reversed diastolic flow in Umbilical artery

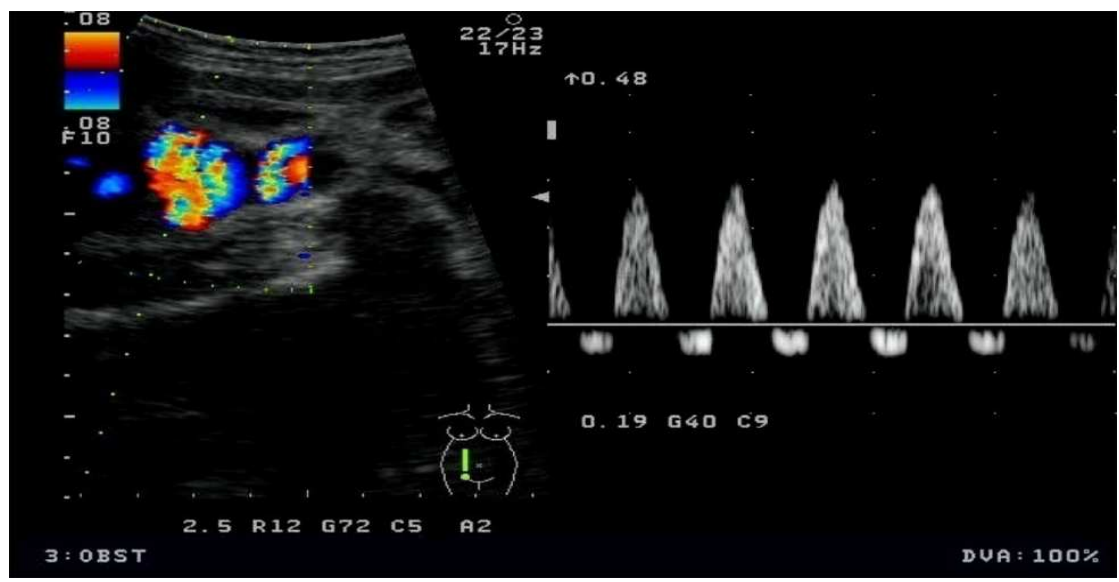

Fetal MCA is a low resistance circulation throughout pregnancy [14][15] and accounts for 7\% of fetal cardiac output (fig-4). In fetal hypoxia and ischemia increase in diastolic flow with decreased pulsatility index shows the brain sparing taking place in compromised fetuses [3] (fig-5)

Fig.- 4: Middle cerebral artery normal velocimetry

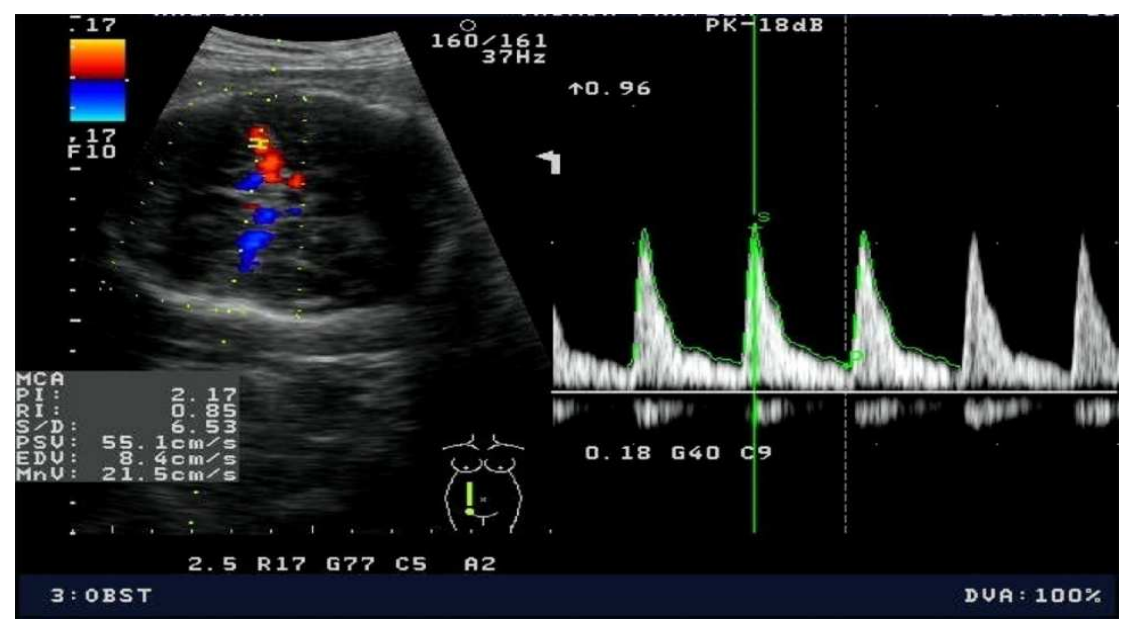

Fig.-5: Increased diastolic flow in Middle Cerebral artery

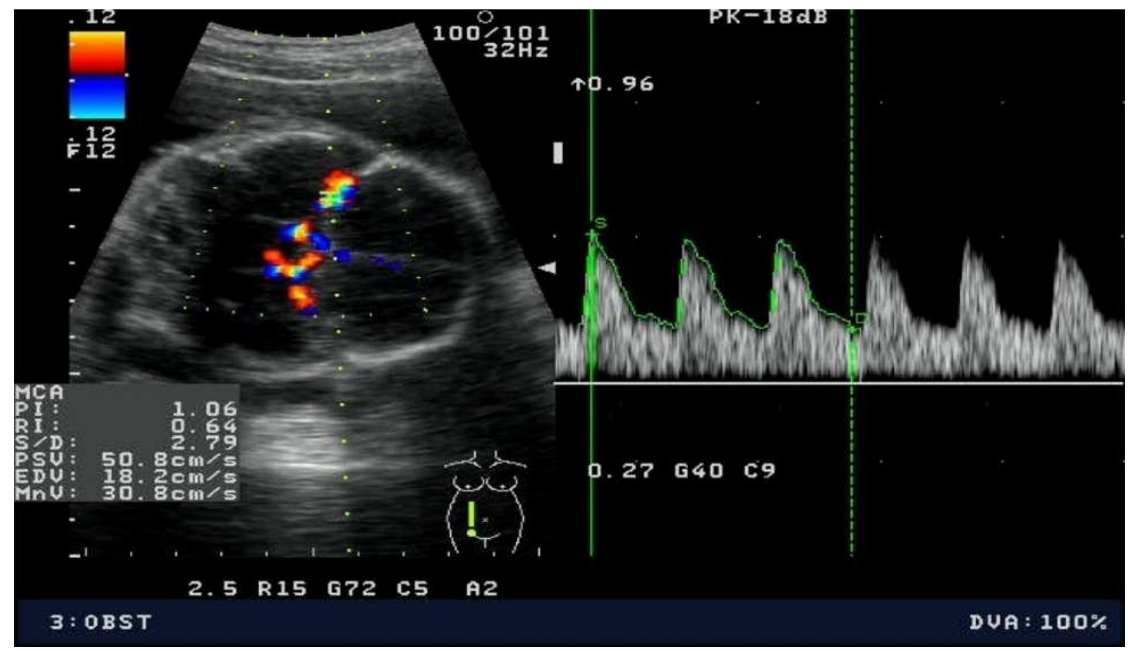

Fetal hypoxia results in to adverse fetal outcome. Adverse fetal outcome is divided in to two groups major and minor adverse fetal outcome on the basis of severity [11]. 
We studied the diagnostic and prognostic value of different color doppler indices in term of sensitivity, specificity, Positive predictive value, negative predictive value and accuracy in prediction of adverse fetal outcome.

We found UA S/D ratio $\geq 3$ and $\mathrm{PI} \geq 95$ percentile as most sensitive and carry highest negative predictive value. This result is comparable with the study result of Lakhkar BN et al [3], Fong KW et al [8] and Strigini FAL et al [14]

[Table-4].

Table No 4: Performance characteristic of Umbilical artery, fetal aorta and middle cerebral artery in prediction of adverse perinatal outcome.

\begin{tabular}{|c|c|c|c|c|c|c|}
\hline \multicolumn{2}{|c|}{ Parameter assessed } & Author & Se & Sp & PPV & NPV \\
\hline \multirow[t]{3}{*}{ UAPI } & $>2 \mathrm{SD}$ & Fong [8] & 44.7 & 86.6 & 54 & 86.7 \\
\hline & $>2 \mathrm{SD}$ & Lakhkar[3] & 50 & 59 & 66.6 & 81.7 \\
\hline & $>95$ percentile & Present study & 80 & 70.77 & 59.57 & 41.9 \\
\hline \multirow[t]{4}{*}{ UAS/D } & $>2 \mathrm{SD}$ & Strigini[14] & 53 & 94 & 40 & 96 \\
\hline & $>2 \mathrm{SD}$ & Lakhkar[3] & 66.6 & 45.4 & 66.6 & 45.4 \\
\hline & $>3$ & Present study & 86.96 & 71.21 & 51.28 & 94 \\
\hline & $>95$ percentile & Present study & 69.57 & 78.78 & 53.33 & 88.14 \\
\hline \multirow[t]{4}{*}{ MCA PI } & $<1.5 \mathrm{SD}$ & Strigini[14] & 40 & 95 & 36 & 95 \\
\hline & $<2 \mathrm{SD}$ & Fong[8] & 72.4 & 58.1 & 37.7 & 85.7 \\
\hline & $<2 \mathrm{SD}$ & Lakhkar[3] & 41.6 & 90.9 & 88.2 & 48.7 \\
\hline & $<5$ percentile & Present study & 47.06 & 1.81 & 57.14 & 75 \\
\hline
\end{tabular}

MCA /UA PI Ratio <1.8 was found to be highly specific and most accurate. This result is comparable with the study result of Lakhkar BN et al [3], Fong KW et al [8],Bahado Singh RO et al [15] and Odibo AO et al [16] [Table-5].

Table No 5: Performance characteristic of MCA/UA( PI,S/D) ratio in prediction of adverse perinatal outcome

\begin{tabular}{|l|l|l|l|l|l|l|}
\hline \multicolumn{2}{|l|}{ Parameter assessed } & Author & Se & Sp & PPV & NPV \\
\hline PI & $<2$ SD & Bahado Singh[15] & 63 & 90 & 81 & 77 \\
\cline { 2 - 7 } & $<5$ percentile & Odibo[16] & 65 & 73 & 73 & 65 \\
\cline { 2 - 7 } & $<1.08$ & Odibo[16] & 72 & 62 & 68 & 67 \\
\cline { 2 - 7 } & $<2$ SD & Fong[8] & 51.3 & 80.6 & 48.1 & 82.5 \\
\cline { 2 - 7 } & $<1$ & Lakhkar[3] & 47.2 & 86.3 & 85 & 50 \\
\cline { 2 - 7 } & $<1.08$ & Present study & 73.53 & 89.4 & 78.12 & 86.76 \\
\cline { 2 - 7 } & $<2$ SD & Present study & 77.14 & 83.08 & 71.05 & 87.1 \\
\hline \multirow{4}{*}{ S/D } & $<1$ & Lakhkar[3] & 55.5 & 72.7 & 76.9 & 50 \\
\cline { 2 - 7 } & $<1$ & Present study & 47.83 & 84.84 & 52.38 & 82.35 \\
\hline
\end{tabular}

Absent end diastolic flow (AEDF) or reversed end diastolic flow (REDF) in umbilical artery and DAA was most specific $(100 \%)$ and highest positive predictive value $(100 \%)$.

Absent end diastolic flow (AEDF) or reversed end diastolic flow (REDF) in umbilical artery and DAA was associated with $100 \%$ mortality in our study group. Same result was also found in study of Lakhkar BN et al [3], Narula Harneet et al [17] and Bhatt CJ et al [18] (fig-6).

Fig. 6: Perinatal mortality in subject having absent or reversed end diastolic flow in descending fetal aorta and umbilical artery. 


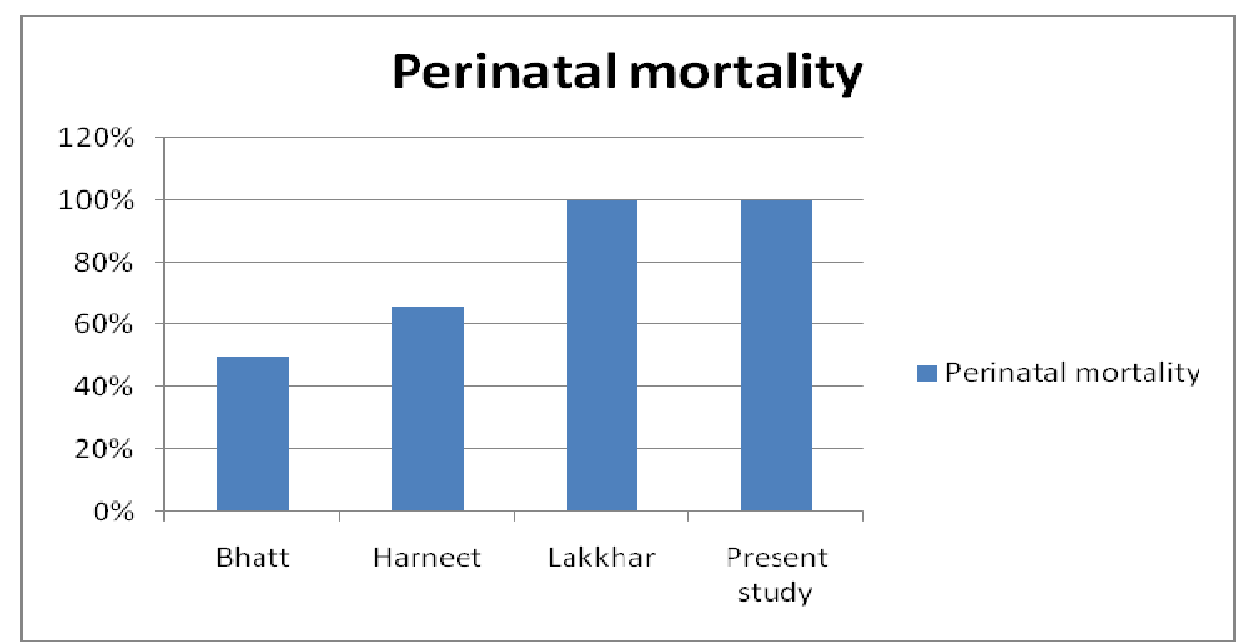

\section{Conclusion}

The prevalence of low birth weight in India is approximately $26 \%$ and out of this the proportion of low birth weight due to IUGR is approximately $54.2 \%$. [19], to do find out how-much the IUGR \& PIH has affected the fetus and to timely intervene, various Doppler indices have been - proposed by various authors. For the prediction of adverse perinatal outcome in women with PIH \& IUGR, the best Doppler indices, according to our study are UA SD Ratio (cut off $\geq 3$ ), MCA / UA PI < 1.08 and AEDF / REDF abnormal flow pattern in UA and DAA which should always be mentioned on the USG with color Doppler report of patients with PIH \& IUGR. A timely Doppler study of pregnancy for these indices will help to reduce the perinatal morbidity \& mortality in PIH and IUGR fetuses.

\section{Funding: Nil,Conflict of interest: None. Permission of IRB: Yes}

\section{References}

1. Habek D, Jugović D, Hodek B, Herman R, Maticević A, Habek JC, Pisl Z, Salihagić A. Fetal biophysical profile and cerebro-umbilical ratio in assessment of brain damage in growth restricted fetuses. Eur J Obstet Gynecol Reprod Biol. 2004 May 10;114(1):29-34.

2. Stuart B, Drumm J, Fitzgerald DE and Duignan NM. Fetal blood velocity waveforms in normal pregnancy. British journal of obstetrics and Gynaecology, Sep 1980, Vol. 87, pp.780-5.

3. Lakhkar BN, Rajagopal KV, Gourisankar PT. Doppler Prediction of Adverse Perinatal Outcome in PIH and IUGR. IJRI 2006 16:1:109-116.
4. Gramellini D, Folli MC, Raboni S, Vadora E, Merialdi A. Cerebral-umbilical Doppler ratio as a predictor of adverse perinatal outcome. Obstet Gynecol. 1992 Mar;79(3):416-20.

5. Chauhan R, Samiksha Trivedi- Role of Doppler study in high risk pregnancy- Journal of obstetric and gynecology of india Vol 52, No.30:may/june 2002.

6. Mari G, Deter RL. Middle cerebral artery flow velocity waveforms in normal and small-forgestational-age fetuses. Am J Obstet Gynecol. 1992 Apr;166(4):1262-70.

7. Ott WJ. Comparison of the non-stress test with the evaluation of centralization of blood flow for the prediction of neonatal compromise. Ultrasound Obstet Gynecol. 1999 Jul;14(1):38-41.

8. Fong KW, Ohlsson A, Hannah ME, Grisaru S, Kingdom J, Cohen H, Ryan M, Windrim R, Foster G, Amankwah K. Prediction of perinatal outcome in fetuses suspected to have intrauterine growth restriction: Doppler US study of fetal cerebral, renal, and umbilical arteries. Radiology. 1999 Dec;213(3):681-9.

9. Acharya G, Wilsgaard T, Berntsen GKR, Maltau M, Kiserud T. Reference ranges for serial measurements of umbilical artery doppler indices in second half of pregnancy. Am J Obstet Gynecol. 2005 192:154-8.

10. Piazze J, Padula F, Cerekja A, Cosmi EV, Anceschi MM. Prognostic value of umbilical-middle cerebral 
artery pulsatility index ratio in fetuses with growth restr iction. Int J Gynaecol Obstet. 2005 Dec;91(3):233-7. Epub 2005 Oct 7.

11. Rizvi S.M.R.,Iqbal Nasir,Yasmeen Naila. Small for gestational age fetus Role of colour Doppler in Ultrasund in the management. Professional Med J Dec 2006; 13(4);705-709.

\section{Ertan AK, He JP, Tanriverdi HA, Hendrik} J, Limbach HG, Schmidt W. Comparison of perinatal outcome in fetuses with revers e or absent enddiastolic flow in the umbilical arteryand/or fetal descending aorta. J Perinat Med. 2003;31(4):307-12.

13. Gerber S, Hohlfeld P, Viquerat F, Tolsa JF, Vial Y. Intrauterine growth restriction and absent or reverse end-diastolic blood flow in umbilical artery (Doppler class II or III): A retrospective study of short- and longterm fetal morbidity and mortality. Eur J Obstet Gynecol Reprod Biol. 2006 May 1;126(1):20-6. Epub 2005 Aug 31.

14. Strigini FA, De Luca G, Lencioni G, Scida P, Giusti G, Genazzani AR. Middle cerebral artery velocimetry: different clinical relevance depending on umbilical velocimetry. Obstet Gynecol. 1997 Dec;90(6):953-7.

15. Bahado Singh RO, Kovanci E, Jeffres A et al.The Doppler cerebroplacental ratio and perinatal outcome in intrauterine growth restriction. American Journal of Obstetric \& Gynecol 1999; 180: 750-6.

16. Odibo AO, Riddick C, Pare E, Stamilio DM, Macones GA. Cerebroplacental Doppler ratio and adverse perinatal outcomes in intrauterine growth restriction: evaluating the impact of using gestational age-specific reference values. J Ultrasound Med. 2005 Sep;24(9):1223-8.

17. Narula Harneet, Kapila AK, Mohi Manjeet Kour. Cerebral and umbilical arterial blood flow velocity in normal and growth retarted pregnancy. Obstet Gynecol India Vol. 59,No.1: January/Fabruary 2009 pg 47-52.

18. Bhatt CJ Arora J,Shah M.S. Role of colour Doppler in pregnancy induced hypertention(a study of 100 cases). Indian journal of radiology imaging 2003 Vol.13, issue-4 pg 417-420.

19. Acharya D, Nagraj K,Nair NS, Bhatt HV. Maternal Determinants of intrauterine growth retardation: a case control study in Udupi district Karnataka. Indian journal of community medicine 2004;29(4):10-12.

\section{How to cite this article?}

Netam SBS, Abha S, Mandle H, Dutt V, Kumar S, Singh R. Best color Doppler indices in prediction of fetal hypoxia in IUGR fetuses. Int J Med Res Rev 2015;3(9):1012-1019. doi: 10.17511/ijmrr.2015.i9.187. 